\title{
Abordagem Humanizada em UTIs dos Cursos de Fisioterapia Brasileiros: Disposição das Disciplinas e Considerações Docentes
}

\author{
Erica de Araújo Figueiredo ${ }^{1}$, Ana Lúcia Leal ${ }^{2}$
}

\begin{abstract}
RESUMO
A Fisioterapia faz parte das ciências da saúde. Destina-se à prevenção e ao tratamento de alterações de órgãos e sistemas. Na Unidade de Terapia Intensiva (UTI), o fisioterapeuta intensivista atua na função do sistema respiratório e de outros sistemas, precisando estar preparado para se deparar com a especificidade e a complexidade do ambiente hospitalar, não apenas no manejo das técnicas, mas também sendo sensível à necessidade de cultivar uma relação humanizada com seus pacientes. O presente estudo teve por objetivo verificar os Projetos Políticos Curriculares (PPCs) das Instituições de Ensino Superior (IESs) dos cursos de Fisioterapia de todo o país, disponibilizados em seus respectivos sites, compreendendo a disposição das disciplinas de UTI e Humanização na grade curricular dos cursos, e verificar se a abordagem humanizada na formação teórica é considerada pelos professores como fator que contribui, efetivamente, para a prática em UTIs. Realizamos uma entrevista semiestruturada com quatro docentes em duas IES da cidade de Recife. Os resultados da análise dos PPCs pesquisados apontaram para uma formação teórica escassa na área da humanização terapeuta-paciente. As entrevistas realizadas com os professores apontaram para um reconhecimento unânime da importância da área, porém nenhum deles mencionou se havia uma disciplina específica para tratar sobre a questão com os alunos nas IESs em que atuavam.
\end{abstract}

Palavras-chave: Fisioterapia. Currículo. Unidade de Terapia Intensiva. Humanização.

HUMANIZED APPROACH IN ICUS OF BRAZILIAN PHYSIOTHERAPY COURSES: DISPOSITION OF DISCIPLINES AND TEACHING CONSIDERATIONS

\begin{abstract} students in the HEI who acte.

Physical therapy is part of the health sciences. It is intended to prevent and treat changes in functions and systems. In the Intense Care Unit (ICU), the intensivist physiotherapist in the function of the respiratory system and other systems, needing to be prepared to come face to face with a specificity and complexity of the hospital environment, only not managing the techniques, but also with his patients. The objective of this study was, to analyze the Curricular Political Projects (CPP) of Higher Education Institutions (HEI) s of the Physical therapy. Courses of the whole Country, made available on their websites, including one of the ICU and Humanization disciplines in the curricular curriculum of the Courses, and verify that humanization in the training of teachers is done by teachers as what effectively does for a practice in ICUs. A semi-structured interview was, conducted in four professors at two HEl's in the city of Recife. The results of the analysis of the PPCs surveyed pointed to a scarce theoretical formation in the area of therapist-patient humanization. As the interviews with the teachers pointed to a recognition of their situation, little more than the teacher mentioned that it was a discipline to deal with the issue with the

Keywords: Physical therapy. Curricular Political Projects. Intense Care Unit. Humanization. 


\section{INTRODUÇÃO}

A Fisioterapia faz parte das ciências da saúde e se destina à prevenção e ao tratamento de alterações recorrentes em órgãos e sistemas, em destaque às doenças ósseas e musculares (COFFITO, 2011). A Fisioterapia na Unidade de Terapia Intensiva (UTI) atua de maneira complexa na função do sistema respiratório e em todas as atividades envolvidas na melhora desta função. Chamada de Fisioterapia Cardiorrespiratória, o fisioterapeuta que atua nesta área promove a diminuição de riscos de complicações respiratórias, infecções hospitalares e das vias respiratórias, reduzindo o sofrimento do paciente.

A Fisioterapia na UTI busca a manutenção das funções vitais, bem como a prevenção e/ou tratamento das doenças cardiopulmonares, circulatórias e musculares, reduzindo a chance de possíveis complicações clínicas. Além disso, atua na melhora do suporte ventilatório, com a monitorização contínua dos gases que entram e saem dos pulmões, no aumento da força muscular e na redução de retrações de tendões, evitando contraturas e a formação de úlceras. Esta intervenção favorece a redução do tempo de internação e de gastos com medicamentos, o que significa a diminuição de custos com a saúde em geral (ASSOBRAFIR, 2008).

Para Cachioni et al. (2014), o fisioterapeuta é parte fundamental no processo de reabilitação, prevenção ou estimulação do desenvolvimento e utiliza como modelo o seu corpo e a sua voz. Por meio de comandos verbais e técnicas específicas de controle corporal, visa a auxiliar o paciente a realizar posturas corporais adequadas, sem correr o risco de lesar o próprio corpo. Pela importância deste profissional, é necessária uma reflexão constante sobre como se dá a sua formação.

As áreas possíveis de atuação são: Fisioterapia Clínica, atuando em ambulatório, consultório, centros de reabilitação, hospitais e clínicas; Saúde Coletiva, atuando nas ações básicas, fisioterapia do trabalho, programas institucionais, vigilância sanitária; Esporte; Indústria e Comércio de equipamentos e produtos para fisioterapia; Educação, na direção e coordenação de cursos, docência nos níveis secundário e superior, extensão, pesquisa, supervisão técnica e administrativa (COFFITO, 2011).

Guedes, Alves e Wyszomirska (2013) consideram que o professor fisioterapeuta, com formação strictu senso, apresentava uma visão clara das atuais necessidades na educação, porém, nas práticas pedagógicas, poderiam apresentar traços tradicionais, com aulas expositivas focadas nele, apresentando dificuldades para adotar estratégias inovadoras na aprendizagem.

O fisioterapeuta intensivista precisa estar preparado para se deparar com toda a especificidade e complexidade que existe no ambiente hospitalar, não apenas estando habilitado no manejo das técnicas, mas também sendo sensível à necessidade de cultivar uma relação humanizada com seus pacientes. Gallian (2002) considera que a reflexão acerca da importância de uma abordagem humanizada surgiu para sensibilizar o profissional da área da saúde em relação a evitar o distanciamento com seus pacientes.

Para Martins (2003), uma abordagem humanizada envolve questões singulares, como emoções, crenças e valores que, infelizmente, passaram, muitas vezes, para um segundo plano, mediante o desenvolvimento tecnológico na saúde. Neste sentido, a assistência se desumanizou, passando a doença a ser objeto puramente do saber. Muitos problemas, porém, podem ser resolvidos, ou atenuados, se os pacientes se sentirem compreendidos e respeitados pelos profissionais. $\mathrm{O}$ autor considera que $\mathrm{o}$ abandono e a rejeição ao tratamento podem estar relacionados à falta de acolhimento e moderação dos gestos e da fala por parte do profissional.

Concordamos com Alves (2003), quando declarou: "O que as pessoas mais desejam é alguém que as escute de maneira calma e tranquila. E silêncio. Sem dar conselhos [...]. A gente ama não a pessoa que fala bonito. É a pessoa que escuta bonito" (p. 65).

Com vistas a ressaltar a importância de uma formação de qualidade para atender à realidade que se apresentar, decidimos pesquisar como se dava o processo de formação dos futuros fisioterapeutas, que deveria transcender o meramente técnico e contemplar, também, os aspectos humanos.

Grosseman e Patrício (2003), em um estudo sobre a humanização como subsídio para a educação médica, observaram que durante a formação acadêmica os profissionais aprendem a buscar o objeto "doença" nos pacientes. Declararam que sentem falta de estimular seus potenciais de se relacionar com o outro, além da presença das limitações que apontaram no processo do ensino e aprendizagem, que se referiam à subjetividade do outro. Com isso, deixaram claro que, até mesmo quem está ainda em formação na área médica, sente necessidade de ter mais conteúdo didático sobre a relação subjetiva entre o médico e o paciente. 
Pelo fato de o docente ser o principal mediador entre a motivação do discente e o planejamento a ser desenvolvido, torna-se sua a responsabilidade de identificar os interesses do aluno, suas dificuldades e necessidades, procurando influenciá-los positivamente por meio de suas experiências.

Formar profissionais fisioterapeutas com capacidade de pensamento humanista e reflexivo é necessário para que possam agir em todos os níveis de atenção à saúde. Neste sentido, concordamos com Sumyia e Jeolás (2010), quando ressaltaram a necessidade de compreendermos a técnica como um instrumento que deve acolher o paciente e não o excluir. O objetivo não deveria ser meramente agir sobre ela, mas também evitar as relações objetivadas que obliteram a subjetividade.

Entendemos que apenas o aparato técnico se mostra insuficiente, necessitando inserir oficialmente o conteúdo humanista na formação do fisioterapeuta. Pela complexidade de sua atuação, portanto, faz-se necessário destacar a relevância de uma formação acadêmica ampla, com vistas a minimizar os aspectos negativos e a servir à sociedade de modo competente e acolhedor. Manter uma relação satisfatória com o paciente e seus familiares parece estar ligado à recuperação daquele, sendo fundamental que esse conhecimento seja transmitido aos novos profissionais de Fisioterapia durante a sua vida acadêmica. Abordar esse tema deixa claro que ele faz parte de uma formação ampla e integral, sendo um aspecto fundamental à formação, com vistas a atender as demandas de nossa sociedade.

Buscar verificar de que maneira as disciplinas estão distribuídas no currículo dos cursos de Fisioterapia do país, pode nos dar pistas para identificar de que modo o ensino/avaliação adotados estão sendo empregados. Neste sentido, o presente estudo teve por objetivo verificar os Projetos Políticos Curriculares (PPCS) das IES dos cursos de Fisioterapia de todo o país, disponibilizados em seus respectivos sites, compreendendo a disposição das disciplinas de UTI e Humanização nas grades curriculares. Além disso, intencionávamos checar se a abordagem humanizada na formação teórica era considerada pelos professores como fator que contribuía, efetivamente, para a prática em UTIs.

\section{METODOLOGIA}

Realizamos uma pesquisa documental com vistas a analisar se havia disciplinas que abordavam o tema humanização. Catalogamos nas planilhas do programa Excel todas as IES do território Nacional que possuíssem o curso de Fisioterapia e os períodos em que as disciplinas de UTI e de Humanização eram ministradas.

Para Gil (2008), a pesquisa documental caracteriza-se por dados obtidos de maneira indireta que tomam forma de documentos. Em outro estudo, o autor (2002) considera que ela inclui materiais que ainda não receberam um tratamento analítico ou que ainda podem ser reelaborados de acordo com o objeto da pesquisa. As fontes são constituídas por materiais diversificados e dispersos. Ela apresenta vantagens por ser uma fonte rica e estável de dados, não exigir contato com o sujeito e ser de baixo custo, exigindo apenas a capacidade e a disponibilidade de tempo do pesquisador.

Muitos autores referem-se à pesquisa documental como sendo sinônimo da pesquisa bibliográfica. Oliveira (2007) realiza uma boa distinção entre ambas, ao especificar que a pesquisa bibliográfica faz análise de documentos de domínio científico, como periódicos, enciclopédias, dicionários e artigos científicos, ou seja, um estudo direto de fontes científicas que não recorre a fatos/fenômenos da realidade. 0 pesquisador está em contato direto com a obra. Já na pesquisa documental, que foi o caso de nossa proposta, a busca da informação ocorre em documentos que nunca receberam tratamento científico.

Em nossa pesquisa realizamos entrevistas semiestruturadas. Três professores da disciplina de Terapia Intensiva da IES1 e um professor da IES2 as responderam, com vistas a refletir sobre o tema Humanização nos cursos de Fisioterapia.

Todas as IESs eram particulares e estavam localizadas na Cidade do Recife, PE. Essas Instituições ministravam outros cursos na área da saúde e possuíam Clínicas Escolas em suas dependências, que são onde os alunos têm os primeiros contatos com os pacientes durante a Graduação. Quanto aos locais onde ocorreram as entrevistas, dois professores da IES 1 foram entrevistados nas clínicas escolas da própria Instituição a que estão vinculados. O terceiro foi entrevistado no hospital que exerce a profissão. O quarto professor, da IES 2, também foi entrevistado no hospital onde exerce a profissão. Todas as entrevistas realizadas foram gravadas (somente por áudio) e analisadas posteriormente. É válido ressaltar que os participantes receberam um Termo de Consentimento Livre e Esclarecido - TCLE - para que tivessem ciência de nossa proposta e, assim, contribuíssem espontaneamente. 
Para analisar os dados obtidos nas entrevistas, realizamos o método de Análise de Conteúdo de Laurence Bardin (2004). Esta autora considera o método como sendo:

[...] um conjunto de técnicas de análise das comunicações visando obter, por procedimentos sistemáticos e objetivos de descrição de conteúdo das mensagens, indicadores (quantitativos ou não) que permitam a inferência de conhecimentos relativos às condições de produção/recepção (variáveis inferidas) destas mensagens (p. 37).

Ainda nesta obra, a autora cita que existem duas práticas científicas intimamente ligadas à Análise de Conteúdo pela identidade do objeto e pela aproximação metodológica; são elas: a Linguística e as Técnicas Documentais. Com o intuito de delimitar o campo de ação da Análise de Conteúdo dessas práticas, Bardin (2004) considera que a Linguística estuda a língua para descrever o seu funcionamento, já a Análise de Conteúdo procura conhecer aquilo que está por trás das palavras sobre as quais se debruça, e busca outras realidades por meio das mensagens.

Quanto às Técnicas Documentais, Bardin (2004) especifica que a operação intelectual desta análise está caracterizada pelo recorte da informação, pela divisão em categorias segundo o critério de analogia e a representação sob a forma indexada. Trata-se de fases semelhantes à fase de tratamento das mensagens na Análise de Conteúdo. Existem porém, diferenças, pois a análise documental trabalha com documentos e faz-se principalmente por classificação-indexação e a representação da informação para consulta e armazenagem. Já a Análise de Conteúdo trabalha com mensagens e se estrutura, dentre outras coisas, pela técnica de Análise Categorial Temática e manipula as mensagens para inferir outras realidades.

A Análise de Conteúdo apresenta três fases: 1) a pré-análise, que é a fase de organização; 2) a exploração do material, que é a fase de operação de codificação, desconto ou enumeração em função das regras já formuladas; 3 ) fase do tratamento de resultados obtidos e interpretação, na qual o analista pode adiantar interpretações a propósito dos objetivos ou que digam respeito a descobertas inesperadas. Os resultados obtidos podem, ainda, servir de base a outras análises em torno de novas dimensões teóricas ou praticada a técnica diferentemente. Além das fases, a Análise de Conteúdo apresenta, ainda, seis tipos, que são: Análise Temática ou Categorial, Análise de Avaliação, Análise de Enunciação, Análise de Expressão, Análise de Relações e a Análise do Discurso (BARDIN, 2004).
Esta pesquisa utilizou a Análise Categorial (ou Análise Temática) para interpretação dos dados das entrevistas, nossas unidades de registros. Esse tipo caracteriza-se pela "contagem de um ou vários temas ou itens de significação, numa unidade de codificação previamente determinada" (idem, p. 73).

A coleta de dados somente foi iniciada após a aprovação do Projeto de Pesquisa pelo Comitê de Ética em Pesquisa (CEP) - CAAE 2.159.030 - e quando cronograma proposto foi rigorosamente cumprido. A seguir apresentamos as informações que foram obtidas mediante a análise documental, assim como as entrevistas semiestruturadas. Para efeito de assegurar o sigilo, a identidade dos entrevistados jamais foi revelada e, por este motivo, seus nomes foram substituídos por outros.

\section{RESULTADOS E DISCUSSÃO}

Inicialmente serão expostos os achados de nossa pesquisa documental para, posteriormente, tratarmos sobre as entrevistas realizadas com os professores.

Como resultado da pesquisa documental, realizada no ano de 2016, foram localizadas 570 IESs em todo o Brasil. A seguir apresentamos os achados de cada região.

1) Na Região Nordeste localizamos 148 IESs, e a disciplina "Unidade de Terapia Intensiva (UTI)" apareceu em 82 IESs.

Em relação à temática "Humanização", é importante destacar que não podemos afirmar que a mesma não tenha sido abordada nas Instituições em que não apareceu formalmente nos sites pesquisados, pois o conteúdo poderia estar diluído em outras disciplinas, abordado transversalmente. Neste sentido, sempre que nos referirmos a esta disciplina, apenas consideraremos se esteve ou não explícita na grade curricular das IESs. Na região Nordeste, apenas a Faculdade de Integração do Sertão - FIS -, no Estado de Pernambuco, apresentou essa disciplina em sua grade curricular.

2) Na Região Norte foram localizadas 44 IESs, e a disciplina "Unidade de Terapia intensiva (UTI)" constou na matriz curricular de 16 Instituições. Em contrapartida, a disciplina "Humanização" não apareceu em nenhuma das matrizes analisadas dessa região.

3) Na Região Centro-Oeste localizamos 60 Instituições, e a disciplina de "Unidade de Terapia Intensiva (UTI)" esteve presente em 13 IESs. A de "Humaniza- 
ção" foi mencionada em apenas três: o Centro Universitário de Brasília (Uniceub), a Faculdade de Ensino Superior de Catalão (Cesuc) e a Universidade Católica Dom Bosco. Ainda assim, esta foi a maior concentração da referida disciplina em todo país.

4) A Região Sudeste foi a que apresentou o maior número de Instituições que oferecia o curso de Fisioterapia, totalizando 224, e a disciplina de "Unidade de Terapia Intensiva (UTI)" esteve presente em 53. Em apenas duas era ministrada a disciplina "Humanização" (no Instituto Federal de Educação, Ciência e Tecnologia do Rio de Janeiro - IFRJ - e na Faculdade Dinâmica do Vale do Piranga - Fadip - em São Paulo).

5) A quinta região brasileira, a Sul, apresentava 95 IESs com o curso de Fisioterapia, e a disciplina "Unidade de Terapia Intensiva (UTI)" estava presente em 29 IESs. Nesta região não houve nenhum curso que apresentasse em sua grade curricular a disciplina "Humanização".

Em suma, em todas as regiões do país, segundo as informações colhidas pelos sites das IESs analisadas, houve um número reduzido das disciplinas citadas, o que entendemos como lamentável.

A Tabela 1 apresenta um resumo das informações supratransmitidas.

Tabela 1 - Disposição das disciplinas "UTI" e "Humanização" nos cursos de Fisioterapia no Brasil obtidas por meio de seus respectivos sites.

\begin{tabular}{|c|c|c|c|}
\hline \multirow[t]{2}{*}{ Região } & \multirow{2}{*}{$\begin{array}{l}\text { Total de IES } \\
\text { por região }\end{array}$} & \multicolumn{2}{|c|}{$\begin{array}{l}\text { Disciplinas presentes na } \\
\text { grade curricular }\end{array}$} \\
\hline & & UTI & HUMANIZAÇÃO \\
\hline Nordeste & 148 & $82-55 \%$ & $1-0,6 \%$ \\
\hline Norte & 44 & $16-36 \%$ & 0 \\
\hline Centro Oeste & 60 & $16-26 \%$ & $3-5 \%$ \\
\hline Sudeste & 224 & $54-24 \%$ & $2-0,8 \%$ \\
\hline Sul & 95 & $29-30 \%$ & 0 \\
\hline Total geral de IES & 570 & $197-34 \%$ & $6-1 \%$ \\
\hline
\end{tabular}

Observamos, assim, que se tratava de uma disposição extremamente desigual quando comparamos o total de IES de cada região com o número de disciplinas disponíveis nos sites. É importante ressaltar que a falta de informação sobre as disciplinas e os PPCs em mais da metade das IESs do país pelos seus sites, não nos permitiu concluir se, de fato, elas não existiam ou apenas não estavam sendo divulgadas. Ou seja, algumas IES não disponibilizaram em seus endereços eletrônicos dados sobre ementas, disciplinas, corpo docente ou qualquer outra informação sobre os componentes dos cursos que oferecem, e essa falta de informação é suficiente para não permitir que cheguemos a uma conclusão generalizada e mais assertiva. Não podemos deixar, também, de destacar a importância que os PPCs teriam até mesmo para os candidatos à Graduação na área. Eles poderiam saber, por exemplo, a matriz curricular e a estrutura curricular do curso pretendido, assim como de que maneira é organizado e quais seus objetivos, antes de decidir que carreira seguir.

No que diz respeito à entrevista realizada com os professores de duas IESs, podemos considerar que seus depoimentos foram baseados em suas vivências durante a docência nas Instituições em que trabalhavam e na forma como essa estrutura curricular era desenvolvida.

Como já mencionamos, foram entrevistados três professores fisioterapeutas no município de Recife-PE e seus nomes foram substituídos para manter o sigilo irrestrito dos mesmos. Iremos, a seguir, transcrever os principais comentários a respeito de nossos questionamentos:

A abordagem humanizada foi considerada por todos os professores como de grande importância na formação, porém relataram que havia uma deficiência não somente na disciplina de UTI, mas, de uma forma geral, em toda a estrutura curricular do curso de Fisioterapia.

\section{Professor Abel}

\section{Recorte 1}

Quanto à humanização, eu considero a chave de tudo, pois não lidamos com números, lidamos com pessoas e, na área de saúde, com pessoas fragilizadas, não sendo opcional, mas sim essencial.

\section{Professor Norberto}

Recorte 2

A humanização é importante, não há dúvida, mas eu acho que os alunos não estão preparados. [...] Dentro do conteúdo programático de todas as disciplinas deveriam ter um preparo maior. Saber lidar com quem é um paciente de cuidados paliativos faz parte da humanização. Saber lidar com a morte.

\section{Professor Amilton}

Recorte 3

A humanização é um ponto importante! Nós temos ainda várias barreiras [...] Você tem um paciente que, muitas vezes, entra num ambiente que não tem noção de tempo, de como esse tem- 
po passa, de luz, não existe uma janela, não tem determinados estímulos. [...] ainda porque quando ele entra na terapia intensiva tem determinadas coisas, que mesmo materiais, identificam ele no dia a dia: um relógio, uma pulseira [...] e ele perde o referencial de tudo isso. [...] Uma prática muito comum que a gente vê ainda em muitas UTIs é discutir caso de paciente à beira do leito. A gente não sabe o nível de entendimento que $o$ paciente tem e o quanto isso pode ser difícil para ele. [...] Na verdade, não é um leito, não é um nome, não é um número, é uma pessoa que está ali que você tem que ter respeito. [...] poxa, um dia essa pessoa teve sonhos, teve um nível de cognição, muitas vezes bem elevado e naquele momento está ali...

Entendemos que a temática da humanização, independentemente de estar oficialmente nos currículos de saúde em geral, deve ser abordada na Graduação pelos profissionais da saúde tanto pela contribuição na recuperação do paciente quanto pelo fato de ser um princípio do SUS.

Nunes et al. (2016) definem que os estudos em humanização têm recebido destaque por organizações do mundo todo. Tais estudos vêm sendo foco não apenas para a recuperação dos pacientes, mas também para garantir seu bem-estar psicossocial, o que torna importante a proximidade da equipe multidisciplinar com aqueles, não apenas relacionando-se com os mesmos por meio de aparelhos e monitores.

Para Santuzzi et al. (2013), ações direcionadas à preservação da privacidade, associada a atitudes de respeito, transmitem segurança, proporcionando mais confiança ao paciente para com a equipe, reconhecendo o esforço empreendido por ela. Em nossa pesquisa, nenhum professor mencionou que havia uma disciplina específica para tratar sobre a questão da humanização com os alunos, despertando e aprofundando a temática. O professor Hamilton, por exemplo, destacou que, além de importante, a humanização era um ponto que precisava de modificação em caráter de urgência, principalmente entre os profissionais da saúde que lidam com o paciente.

Esse fato nos faz refletir que pode estar havendo uma falta de clareza quanto à necessidade de direcionar mais a atenção à questão da humanização. Sabemos, por estar estabelecido pela Constituição Federal, artigo primeiro, inciso III, que a humanização precisa estar na base de qualquer processo de intervenção na saúde, principalmente quando se refere à humanização hospitalar (BACKES et al., 2006). 0 tratamento precisa ter essa abordagem para que seja mais efetivo, mas parece que isso não está sendo formal- mente enfatizado. Tanto os professores, que destacam a importância da temática, mas não especificam o porquê, quanto por parte de algumas IES, que oferecem os cursos de Fisioterapia, não direcionam disciplinas específicas para o tema. Isso poderia instigar um olhar mais focado para a humanização, ao oferecer, dentre a relação de disciplinas dos cursos, uma área que se faz tão importante compreender como qualquer outra, como ocorre com a própria disciplina de UTI.

\section{CONSIDERAÇÕES FINAIS}

A Fisioterapia cada vez mais apresenta importância não apenas na área de Terapia Intensiva, mas em várias outras e necessita de ajustes e aprofundamentos. Seus estudos não podem apenas buscar comprovação de técnicas e recursos terapêuticos para prevenir e tratar enfermidades. É necessário também analisar, de forma mais aprofundada, a maneira como os profissionais estão sendo formados na Academia. Neste sentido, há de se direcionar a atenção à estrutura curricular dos cursos, como estão sendo ministrados os conteúdos, tanto em sala de aula quanto na prática, como os alunos avaliam a estrutura e que modificações poderiam contribuir para uma formação mais voltada às necessidades dos pacientes.

Nosso estudo pretendeu conhecer uma pequena parte da realidade da área da Fisioterapia, segundo uma pesquisa documental e entrevistas com professores e, ao término do mesmo, gostaríamos de tecer alguns comentários sobre nossos achados.

No que diz respeito ao interesse em "analisar os PPCs das IES dos Cursos de Fisioterapia de todo o país disponibilizados em seus respectivos sites", nosso primeiro objetivo proposto, podemos considerar que verificamos os resultados obtidos sobre a disposição das disciplinas de UTI e de Humanização e, como foi apresentado, houve um número reduzido das mesmas.

Em relação ao nosso segundo objetivo, que era "verificar se a abordagem humanizada na formação teórica é considerada pelos professores como fator que contribui, efetivamente, para a prática em UTIs", como constatamos, felizmente houve um reconhecimento unânime da importância dela. Entendemos que uma formação puramente técnica não contribui para $\mathrm{o}$ atendimento das necessidades dos pacientes.

É importante destacar que esses dados envolveram a análise de uma pequena parcela de estudantes e professores. Uma pesquisa mais ampla, envolvendo um maior número de alunos, mais IESs, mais professores, certamente seria mais rica e ofereceria outros dados sobre como essas questões estão sendo viven- 
ciadas dentro da sala de aula e nos ambientes de UTIs. Há, portanto, a necessidade de se realizar novos estudos para definir que pontos precisam ser aprofundados com vistas à obtenção de uma melhor aprendizagem. Parece-nos claro que propiciar um atendimento de Fisioterapia em UTIs que associe a eficiência técnica ao trato humanizado, trará incontestáveis ganhos para a qualidade de vida, ou sobrevida, do paciente.

\section{REFERÊNCIAS}

ALVES, R. O amor que acende a luz. [S.I]: Papirus, 2003. Disponível em: https://xa.yimg.com/kq/ groups/18176607/1835753430/name/Livro+O+Amor+Que+Acende+a+Lua+-+Rubem+Alves.pdf. Acesso em: 10 ago. 2016.

ASSOBRAFIR. Associações Brasileira de Fisioterpia Respiratória e Fisioterapia em Terapia Intensiva. Relatório final da comissão de ensino. São Paulo. 2008. Disponível em: http:// www.assobrafir.com.br/UserFiles/File/PDF/Relat_rio_Comiss_o_de_Ensino.pdf. Acesso em: 4 mar. 2016.

BACKES, D. S. et al. A humanização hospitalar como expressão da ética. Rev. Latino-Am. Enfermagem, São Paulo, v. 14, n. 1, p. 132-135, jan./fev. 2006. Disponível em: http://www.scielo.br/pdf/rlae/v14n1/v14n1a18. Acesso em: 11 nov. 2017.

BARDIN, L. Analise de conteúdo. 3. ed. São Paulo. Lisboa: Edições 70, 2004.

CACHIONI, L. F. et al. Reflexão sobre o processo de ensino-aprendizagem do fisioterapeuta. Revista da Universidade do Ibirapuera, São Paulo, v. 8, p. 9-17, jul./dez. 2014. Disponível em: https://www.researchgate.net/publication/277711105_REFLEXAO_SOBRE_O_PROCESSO_DE_ENSINOAPRENDIZAGEM_DO_FISIOTERAPËUTA. Acesso em: 26 mar. 2016.

COFFITO. Conselho Federal de Fisioterapia e Terapia Ocupacional. 2011. Definição fisioterapia. Brasília. 1969. Disponível em: http://coffito.gov.br/nsite/?page_id=2341. Acesso em: 4 mar. 2016.

GALLIAN, D. M. C. A (re) humanização da medicina. Psiquiatria na Prática Médica, São Paulo, v. 34, n. 4. 2002. Disponível em: http://www2.unifesp.br/dpsiq/polbr/ppm/especiaI02a.htm. Acesso em: 31 ago. 2016.
GIL, A. C. Como elaborar projetos de pesquisa. 4. ed. São Paulo: Atlas S.A, 2002. Disponível em: https://professores. faccat.br/moodle/pluginfile.php/13410/modresource/content/1/como_elaborar_projeto_de_pesquisa_-_antonio_ carlos_gil.pdf. Acesso em: 27 jun. 2016.

GIL, A. C. Métodos e técnicas de pesquisa social. 6. ed. São Paulo: Atlas, 2008. 200p. Disponível em: http://www.uece. $\mathrm{br} /$ nucleodelinguasitaperi/dmdocuments/gil_metodos_ de_pesquisa.pdf. Acesso em: 27 jun. 2016.

GROSSEMAN, S.; PATRÍCIO, Z. M. A relação médico paciente e o cuidado humano: subsídios para promoção da educação médica. Revista Brasileira de Educação Médica, Rio de Janeiro, v. 28, n. 2, maio/ago. 2003. Disponível em: http:// Itc-ead.nutes.ufrj.br/constructore/objetos/relacao_medico_paciente.pdf. Acesso em: 11 nov. 2016.

GUEDES, M. J. P.; ALVES, N. B.; WYSZOMIRSKA R. M. A. F. Ensino e prática da fisioterapia aplicada à criança na formação do fisioterapeuta. Fisioter. Mov. Curitiba, v. 26, n. 2, p. 291-305, abr./jun. 2013. Disponível em: http://www.scielo. $\mathrm{br} / \mathrm{pdf} / \mathrm{fm} / \mathrm{v} 26 \mathrm{n} 2 / 06 . p d f$. Acesso em: 4 mar. 2016.

MARTINS, M. C. F. N. Humanização da assistência e formação do profissional de saúde. Psychiatry on-line Brasil, v. 8, n. 5, 2003. Disponível em: http://www.polbr.med.br/ ano03/artigo0503_1.php. Acesso em: 31 ago. 2016.

NUNES, A. S. C. et al. A importância do atendimento humanizado em unidade de terapia intensiva. Int. Rev. Cie. Facol/Iseol, Rio de Janeiro, v. 3, n. 1, p. 155-62, 2016. Disponível em: http://www.facol.br/integrada/ed001_2016/ v3_n1_2016_06_art010_NUNES.pdf.

OLIVEIRA, M. M. Como fazer pesquisa qualitativa. Petrópolis: Vozes, 2007. 192p.

SANTUZZI, C. H. et al. Aspectos éticos e humanizados da fisioterapia na UTI: uma revisão sistemática. Fisiot. Mov., v. 26, n. 2, p. 415-422, abr./jun. 2013. Disponível em: http:// www.scielo.br/pdf/fm/v26n2/19.pdf. Acesso em: 27 nov. 2017.

SUMYIA, A.; JEOLÁS, L. S. Processo de mudança na formação do fisioterapeuta: as transições curriculares e seus desafios. Acta Scientiarun Human and Social Sciences, Paraná, v. 32, n. 1, p. 47-53. 2010. Disponível em: http://www2.unifesp.br/dpsiq/polbr/ppm/index.htm. Acesso em: 31 ago. 2016. 